\title{
ARM ROBOT PEMINDAH BARANG (AtwoR) MENGGUNAKAN MOTOR SERVO MG995 SEBAGAI PENGGERAK ARM BERBASIS ARDUINO
}

\section{ROBOT ARM GOODS MOVING (AtwoR) USES MG995 SERVO MOTOR AS ARDUINO BASED ARM DRIVE}

\author{
Andrian $^{1}$, Reni Rahmadewi², Insani Abdi Bangsa ${ }^{3}$ \\ ${ }^{123}$ Universitas Singaperbangsa Karawang \\ 1and.rian16024@student.unsika.ac.id, 22reni.rahmadewi@staff.unsika.ac.id, \\ 3iabdi.bangsa@ft.unsika.ac.i
}

\begin{abstract}
Abstrak
Perkembangan teknologi yang semakin canggih dan pertumbuhan industri yang semakin berkembang di Indonesia. Seiring dengan perkembangan teknologi yang semakin pesat, teknologi robotika mengalami perkembangan yang sangat signifikan. Berbagai macam penelitian tentang robotika secara terus menerus dikembangkan untuk menyempurnakan fungsi robot dalam membantu pekerjaan manusia. Arm robot ini menggunakan arduino yaitu sebagai sistem yang berfungsi mengontrol gerak Arm robot pada robot pemindah barang. Dan untuk pada bagian Arm robot kami menggunakan motor servo MG995, yaitu sebagai aktuator lengan robot yang nantinya akan begerak setelah mengolah data yang dihasilkan oleh sensor warna. Pengujian ini servo pada Arm robot masing - masing berputar yaitu servo1 $90^{\circ}$, Servo2 $360^{\circ}$, servo3 $360^{\circ}$, servo4 $360^{\circ}$. Pada bagian servo 2,3 dan 4 ini berputar secara terus menerus Counter wise $(C W)$ dan Counter Clock Wise $(C C W)$. Hasil dari pengujian masing - masing servo ini pengujian dilakukan menggunakan beban dari $0-700$ gram, dan hasil nilai rata - rata durasi yang didapat masing - masing servo, yaitu servo $1=4.12$ detik, servo2 $=4.75$ detik, servo3= 4.62 detik, servo4= 3 detik. Untuk hasil keseluruhan Arm bergerak, yaitu 16.5 detik, dan masing - masing hasil percobaan 8 kali dengan tingkat keberhasilan 7 kali.
\end{abstract}

Kata kunci : Arm robot, Robot pemindah barang, sensor warna, Motor servo MG995, Arduino.

\begin{abstract}
The development of increasingly sophisticated technology and industrial growth that is increasingly developing in Indonesia. Along with the rapid development of technology, robotics technology is experiencing a very significant development. Various kinds of research on robotics are continuously being developed to improve the function of robots in helping human work. This robot arm uses Arduino as a system that functions to control the robot's motion in the goods moving robot. And for the Arm robot part, we use the MG995 servo motor, which is as an actuator for the robot arm which will move after processing the data generated by the color sensor. This test is the servo on the robot arm, each rotating, namely servo $190^{\circ}$, Servo $2360^{\circ}$, servo $360^{\circ}$, servo $4360^{\circ}$. In the servo 2,3 and 4 it rotates continuously Counter Wise $(\mathrm{CW})$ and Counter Clock Wise $(\mathrm{CCW})$. The results of the test for each servo are carried out using a load of $0-700$ grams, and the results of the average duration value obtained by each servo are servo $1=4.12$ seconds, servo $2=4.75$ seconds, servo3 $=4.62$ seconds, servo $4=3$ second. For the total results of the moving Arm, which is 16.5 seconds, and each experiment results 8 times with an increase of 7 times.
\end{abstract}

Keywords: Arm robot, goods moving robot, color sensor, MG995 servo motor, Arduino. 


\section{Jurnal Electro Luceat [November] [2020]}

\section{PENDAHULUAN}

\subsection{Latar Belakang}

Perkembangan teknologi di era industri yang semakin pesat, berbagai macam teknologi banyak yang baru ditemukan, sampai teknologi perkembangan dari teknologi sebelumnya. Teknologi yang diterapkan berkembang dengan pesat pula yang dimana proses didalamnya menyempurnakan fungsi robot dalam membantu pekerjaan manusia di dunia industri, misalnya pada kelancaran operasional, keamanan lingkungan, ekonomi (biaya produksi), serta mutu produk (produktivitas) [1].

Dalam dunia otomasi fungsi utama robot dalam dunia industri saat ini adalah menggantikan tugas manusia yang berhubungan dengan kegiatan yang berulang-ulang atau repetitif yang membutuhkan daya tahan serta konsentrasi tinggi, terutama untuk melakukan pekerjaan fisik yang berat, memindahkan barang, memposisikan benda dan proses-proses lainnya. Jika seseorang disuruh melakukan suatu kegiatan repetitif maka pekerjaan itu akan terasa menjemukan dan melelahkan sehingga kadang dapat menimbulkan kelalaian yang tidak jarang mengarah pada kecelakaan. Untuk meminimalisasi hal-hal tersebut maka manusia memerlukan robot sebagai pengganti yang mempunyai daya tahan serta konsentrasi yang tinggi terutama dalam mengerjakan pekerjaan yang berulangulang atau repetitif [2].

Dari penjelasan di atas, maka munculah gagasan,ide dan inovasi untuk pembuatan robot pemindah barang. Robot ini dirancang untuk mengambil dan menyimpan barang secara otomatis berdasarkan alamat yang sudah ditentukan untuk membawa/memindahkan barang dari satu tempat ke tempat tujuan dengan menggunakan robot yang berjalan mengikuti garis yang sudah ditentukan (line follower). Robot ini bukan hanya bekerja di suatu tempat gudang atau tempat perindustrian, tetapi bisa juga untuk restoran dan toko - toko sembako sebagai pengantar makanan atau barang.

Salah satunya adalah robot pemindah barang (AtwoR Robot). Robot pemindah barang ini merupakan gabungan dari beberapa segmen dan joint yang dibagian lengan robot dibagi menjadi empat bagian yaitu base, shoulder, elbow dan gripper. Disini untuk lengan robotnya yaitu menggunakan motor servo MG995 sebagai penggerak dari lengan robot tersebut, yang dimana gerak motor servo ini sebagai alat otomatis dimana programnya sudah tertanam didalam mikrokontroller. AtwoR robot ini dilengkapi dengan motor DC, driver motor, sensor warna serta arduino sebagai fungsi untuk memenuhi perancangan dari robot tersebut.

\subsection{Tujuan}

Mengetahui berapa beban yang di dapat motor servo MG995 pada Arm robot pemindah barang AtwoR, mengetahui waktu yang didapat pada motor servo MG995 pada Arm robot pemindah barang AtwoR, serta mengetahui putaran yang didapat motor servo MG995 pada Arm robot pemindah barang.

\subsection{Identifikasi Masalah}

Pekerjaan yang masih secara manual atau dikerjakan oleh manusia. Perlunya inovasi yang dapat mempermudah pekerjaan manusia. Perlunya rancangan sistem untuk mendukung robot pemindah barang (AtwoR robot).

\subsection{Metoda Penelitian}

Yang dijadikan bahan untuk melakukan suatu penelitian yaitu sebagai berikut:

1. Observasi, merupakan teknik pengumpulan data dengan langsung terjun ke lapangan untuk mengamati apa yang terjadi secara langsung di tempat kejadian secara sistematik kejadiankejadian, perilaku, objek-objek yang dilihat dan hal-hal lain yang diperlukan dalam 
mendukung penelitian yang sedang berlangsung. Dalam penelitian ini, peneliti melakukan pengamatan langsung ke lokasi-lokasi yang dianggap perlu dalam penelitian kami.

2. Wawancara, merupakan teknik pengumpulan data yang dilakukan melalui tatap muka dan tanya jawab langsung antara pengumpul data terhadap narasumber/sumber data. Dalam penelitian ini, peneliti melakukan wawancara langsung kepada narasumber yang mengetahui kejadian di lapangan.

3. Sosial Media, adalah salah satu metode pengumpulan data dengan cara melihat beberapa video yang ada di youtube tentang sejauh mana perkembangan teknologi di sebuah perusahaan atau perindustrian.

\section{DASAR TEORI /MATERIAL DAN METODOLOGI/PERANCANGAN}

\subsection{Landasan Teori}

\subsubsection{Motor Servo MG995}

Motor servo merupakan sebuah motor DC kecil yang diberi sistem gear dan potensiometer sehingga dapat menempatkan horn servo pada posisi yang diinginkan. Motor servo prinsipnya mempunyai sistem close loop, di mana posisi dari motor akan di informasikan kembali ke rangkaian control yang ada di dalam motor servo.

Berbeda dengan motor DC, motor servo tidak bergerak kontinu, melainkan menuju sudut tertentu saja dan berhenti di sudut tersebut. Motor ini digunakan untuk aplikasi gerakan-gerakan sudut dari robot, contohnya gerakan lengan, gripper menjepit benda, atau gerakan kaki melangkah [13].

Terdapat dua jenis motor servo yaitu motor servo standard dan motor servo continuous. Motor servo continuous dapat bergerak sampai satu putaran penuh sebesar $360^{\circ}$, sedangkan motor servo standard hanya dapat bergerak sampai setengah putaran yaitu 180 derajat. Pada perancangan Arm pembuatan lengan robot pemindah barang (AtwoR) ini menggunakan motor servo standar $180^{\circ}$ hanya saja sudah diubah agar bisa berputar continuous sebesar $360^{\circ}$. Motor servo jenis ini merupakan motor yang mampu bergerak atau berputar. Lengan robot pemindah barang ini menggunakan 4 buah motor servo jenis MG995 [14].

\subsubsection{Arduino Uno}

Menurut Feri Djuandi (2011:8) "Komponen utama didalam papan Arduino adalah sebuah mikrokontroler 8 bit dengan merk ATmega yang dibuat oleh Atmel Corporation. Berbagai papan Arduino menggunakan tipe ATmega yang berbeda beda tergantung dari spesifikasinya, sebagai contoh Arduino Uno menggunakan ATmega328 sedangkan Arduino Mega 2560 yang lebih canggih menggunakan ATmega2560." [17].

Sifat open source Arduino banyak memberikan keuntungan tersendiri, dikarenakan dengan sifat open source komponen yang digunakan tidak hanya tergantung pada satu merek tetapi juga memungkinkan bisa digunakan dalam semua komponen yang ada dipasaran. Bahasa pemrograman Arduino merupakan bahasa $\mathrm{C}$ yang sudah disederhanakan dengan syntax sehingga dapat mempermudah dalam mempelajari dan mendalami mikrokontroler [19].

\subsubsection{Arduino Nano}

Arduino Nano (Atmega328) adalah papan elektronik open source yang didalamnya terdapat komponen utama, yaitu sebuah chip mikrokontroler Atmega328. Arduino Nano adalah board arduino berukuran kecil, lengkap dan berbasis Atmega328 yang mempunyai kelebihan yang sama 
fungsional dengan Arduino jenis apapun. Cukup hubungkan ke komputer dengan kabel USB atau nyalakan dengan adaptor AC-ke-DC atau baterai untuk memulai [21].

\subsubsection{Regulator LM2596}

Sesuai namanya regulator switching mengatur tegangan keluaran dengan me-nyaklar (ON/OFF) tegangan masukan. Frekuensi switching berbeda-beda pada setiap regulator. Kelebihan regulator switching adalah disipasi daya yang lebih kecil dibandingkan dengan regulator linear karena tujuan utamanya bukan untuk mendisipasikan daya dari selisih tegangan masukan-keluaran. Sedangkan kekurangannya, tegangan keluaran akan bergelombang akibat switching. Oleh karena itu, regulator jenis ini umumnya membutuhkan induktor, kapasitor, dan dioda untuk memperhalus tegangan keluaran. Regulator switching ada 2 jenis; regulator Buck dan regulator Boost. Regulator Buck untuk tegangan keluaran lebih kecil dari tegangan masukan. Regulator Boost untuk tegangan keluaran lebih besar dari tegangan masukan. Salah satu jenis dari regulator Buck adalah LM2596 [9].

\subsubsection{Baterai Lithium Polymer (Li-Po)}

Hampir sama dengan baterai Li- Ion akan tetapi baterai Li-Po tidak menggunakan cairan sebagai elektrolit melainkan menggunakan elektrolit polimer kering yang berbentuk seperti lapisan plastik film tipis. Lapisan film ini disusun berlapis-lapis diantara anoda dan katoda yang mengakibatkan pertukaran ion. Dengan metode ini baterai LiPo dapat dibuat dalam berbagai bentuk dan ukuran. Diluar dari kelebihan arsitektur baterai LiPo, terdapat juga kekurangan yaitu lemahnya aliran pertukaran ion yang terjadi melalui elektrolit polimer kering. Hal ini menyebabkan penurunan pada charging dan discharging rate [23].

\subsubsection{Sensor Warna TCS3200}

Sensor TCS3200 merupakan sensor warna yang bekerja dengan cara membaca nilai intensitas cahaya yang dipancarkan oleh led super bright terhadap objek, pembacaan nilai intensitas cahaya tersebut dilakukan melalui matrik 8x8 photodioda, dimana 64 photo diode tersebut dibagi menjadi 4 kelompok pembaca warna, setiap warna yang disinari led akan memantulkan sinar led menuju photodioda, pantulan sinar tersebut memiliki panjang gelombang yang berbeda -beda tergantung pada warna objek yang terdeteksi [25]. Hal ini yang membuat sensor warna TCS3200 dapat membaca beberapa macam warna.

\subsubsection{Arduino Integrated Development Environment (IDE)}

Arduino IDE merupakan lingkungan terintegrasi yang digunakan untuk melakukan pengembangan. Disebut sebagai lingkungan karena melalui software inilah Arduino dilakukan pemrograman untuk melakukan fungsi-fungsi yang dibenamkan melalui sintaks pemrograman. Arduino menggunakan bahasa pemrograman sendiri dilakukan secara step by step yang menyerupai bahasa C [26]. Bahasa pemrograman Arduino (Sketch) sudah dilakukan perubahan untuk memudahkan pemula dalam melakukan pemrograman dari bahasa aslinya. 


\subsection{Metodologi/Perancangan}

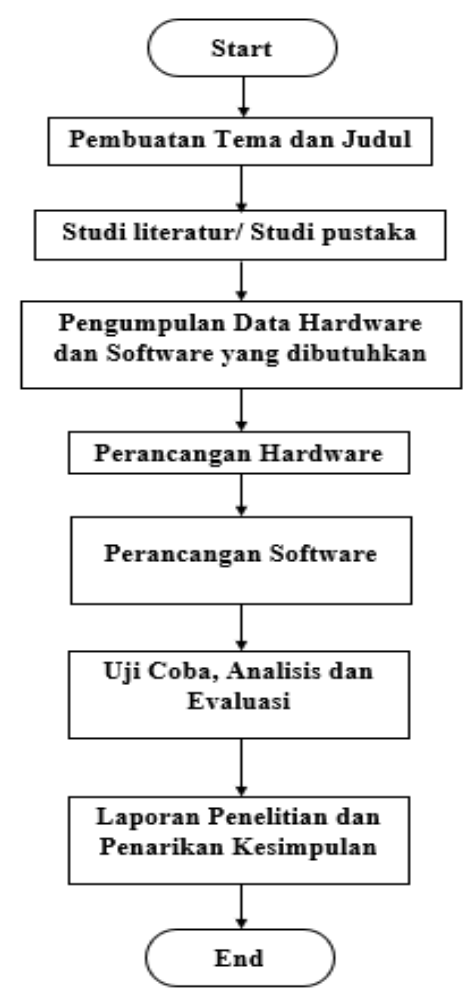

Gambar 1. Metodologi penelitian

\subsubsection{Perancangan Hardware}

Perancangan ini menunjukan bagaimana bentuk dari robot Arm pemindah barang AtwoR. Perancangan pada robot ini bertujuan untuk menampilkan secara keseluruhan dari robot ini agar penelitian ini berjalan dengan baik. Berikut adalah rancangan robot Arm pemindah barang AtwoR:

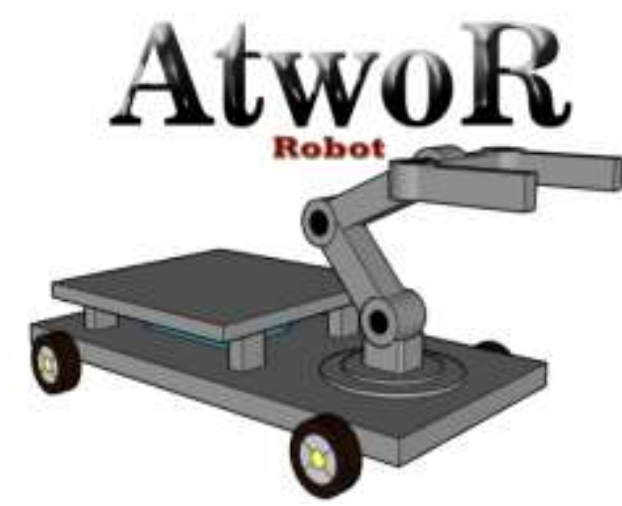

Gambar 2. AtwoR Robot Pemindah Barang

Berikut pada gambar di atas yaitu bentuk fisik dari desain Arm robot pemindah barang AtwoR, yang dimana pada robot tersebut terdapat 4 buah roda, rak untuk menyimpan dan membawa barang ke tempat tujuan, dan yang terakhir tentunya yaitu sebuah rancangan lengan robot untuk mengangkat suatu barang atau objek. 


\subsubsection{Sistem Mekanika}

Material yang digunakan pada arm robot ini yaitu menggunakan plat besi dengan ketebalan 3 $\mathrm{mm}$, bentuk dan dimensi robot dirancang sesuai secara proporsional dengan harapan robot dapat bermanuver dengan baik. Pada gambar 3. adalah free body diagram dari arm robot empat DOF, dan pada umumnya bentuk mekanik dari arm robot ini seperti yang ditunjukan gambar 4

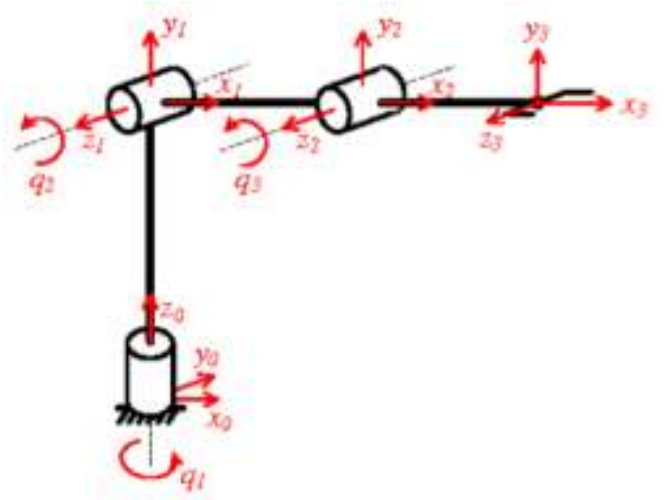

Gambar 3. Free Body Diagram Arm Robot Empat DOF

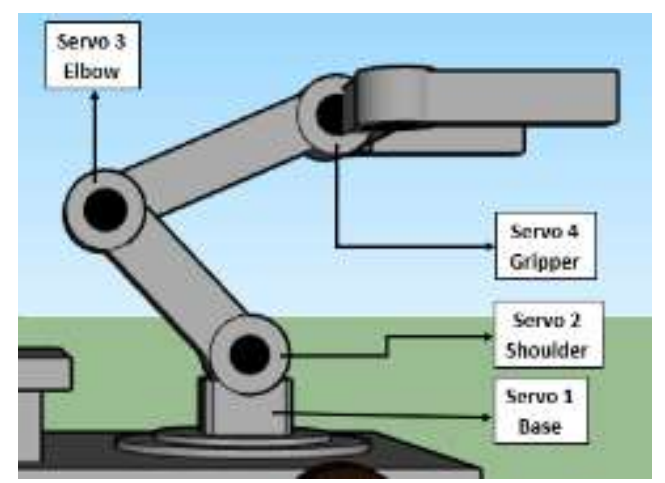

Gambar 4. Bentuk Mekanik Desain Lengan Robot

Pada gambar di atas yaitu struktur joint bentuk desain pada lengan robot yang dimana desain pada lengan ini memiliki 4 DOF yaitu base, shoulder, elbow dan end-effector. Pada bagian lengan terdapat 4 buah motor servo MG995. Untuk bagian servopun berbeda beda diantaranya yaitu: Servo1 (Base), Servo2 (Shoulder), Servo3 (Elbow), dan untuk yang terakhir Servo4 (Gripper).
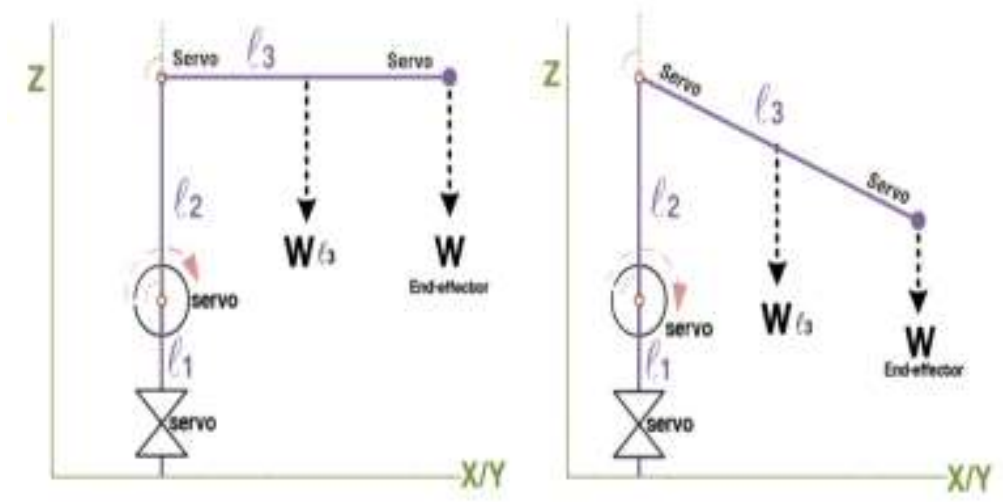

Gambar 5. Struktur Arm Robot Empat DOF 
Pada gambar di atas joint dikendalikan dengan motor servo untuk menggerakan tiap joint. Motor servo bisa berjumlah satu, dua, atau tiga tergantung perancangan yang dibuat dan servo bisa ditempatkan disalah satu sisi joint.

\subsubsection{Perancangan Program}

Pada bagian ini akan dijelaskan bagaimana proses suatu alat yang sudah dibuat baik menggunakan jenis metode skematik, blok diagram atau flowchart.

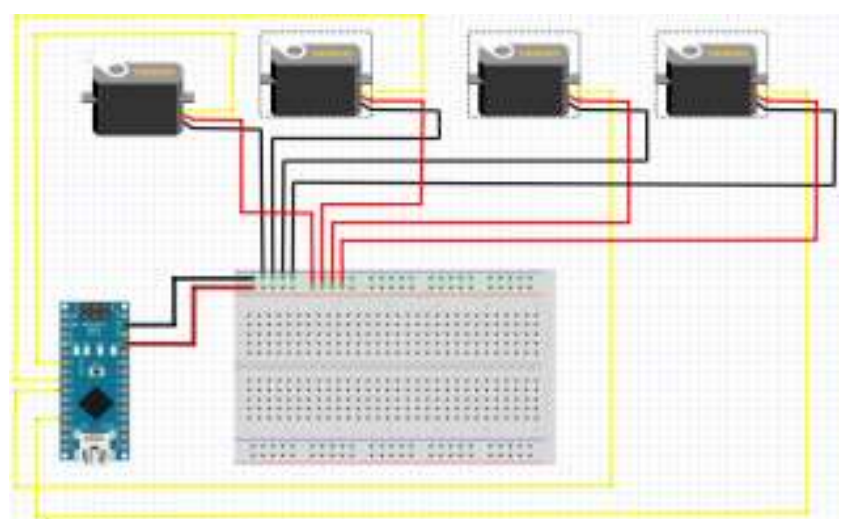

Gambar 6. Skematik Rangkaian Lengan Robot Dengan Servo MG995

Pada gambar di atas merupakan Instrumen elektronik yang digunakan untuk rangkaian ini terdiri dari Arduino Nano, Servo MG995, dan sumber sebagai penggerak Arm lengan robot pada robot pemindah barang AtwoR.

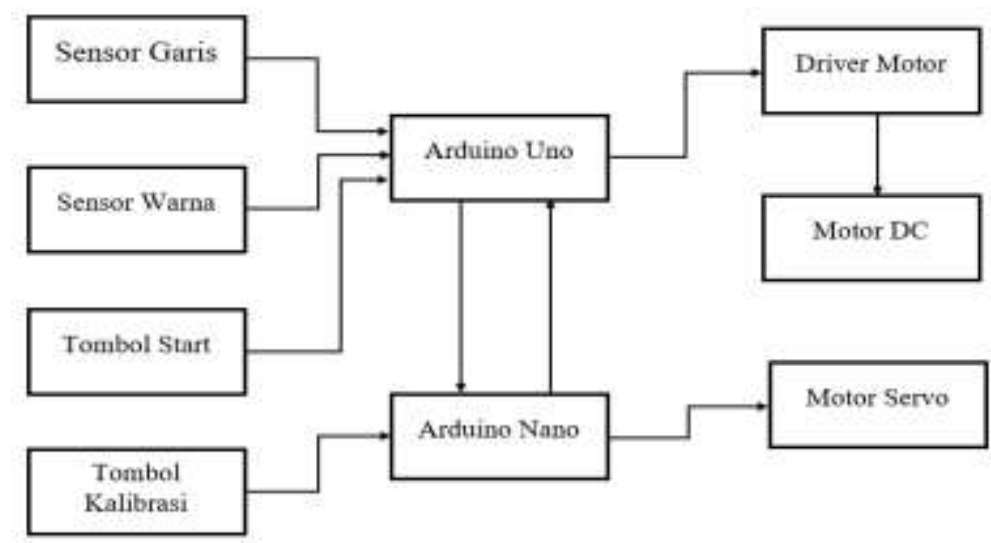

Gambar 7. Gambaran Umum Sistem

Sensor warna berperan sebagai inputan dan outputan dari Arduino Uno, lalu Arduino uno akan meneruskan ke motor driver dan Arduino Nano sebagai pengirim sinyal atau data yang diterima dari sensor warna yang berperan sebagai proses output yang di terima Arduino Nano yang nantinya akan dikirim ke motor servo MG995 yang berperan sebagai penggerak Arm robot pemindah barang (AtwoR). 


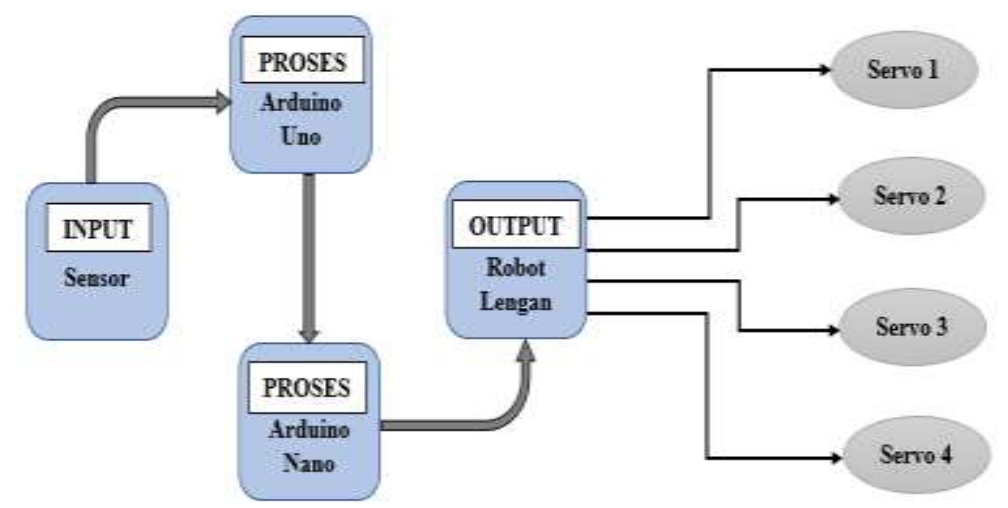

Gambar 8. Blok Diagram Arm pada Lengan Robot Pemindah Barang AtwoR

Gambar di atas menunjukan proses kerja dari sebuah program arm robot yang dimana ada 3 tahap proses sistem kerja dari arm robot tersebut di antaranya yaitu penginputan sensor yang nantinya akan di proses oleh Arduino agar keluarannya atau outputannya berupa Gerakan lengan.

Tabel 1. Sistem Kerja Arm Robot

\begin{tabular}{|c|l|}
\hline Tahapan & \multicolumn{1}{c|}{ Keterangan } \\
\hline Input & $\begin{array}{l}\text { Sensor akan melakukan pendeteksian terhadap benda yang telah } \\
\text { disediakan, kemudian data yang dimiliki oleh sensor di proses oleh } \\
\text { mikrokontroler Arduino. }\end{array}$ \\
\hline \multirow{3}{*}{ Proses } & $\begin{array}{l}\text { Mikrokontroler Arduino akan memproses data yang dimiliki sensor } \\
\text { dengan menggunakan metode inverse kinematics, dimana output } \\
\text { yang dihasilkan berupa gerakan dari robot lengan. }\end{array}$ \\
\hline & $\begin{array}{l}\text { Gerakan Lengan akan mengatur posisi berdasarkan titik koordinat } \\
\text { telah ditentukan. Penentuan posisi atau titik koordinat dibagi menjadi } \\
4 \text { titik koordinat dimana titik koordinat pertama merupakan titik } \\
\text { poros dari robot lengan atau disebut dengan Base, titik kedua } \\
\text { shoulder, titik ketiga Elbow dan titik keempat adalah Gripper yang } \\
\text { berfungsi sebagai titik tujuan barang yang akan dipindahkan dari titik } \\
\text { awal. }\end{array}$ \\
\hline
\end{tabular}




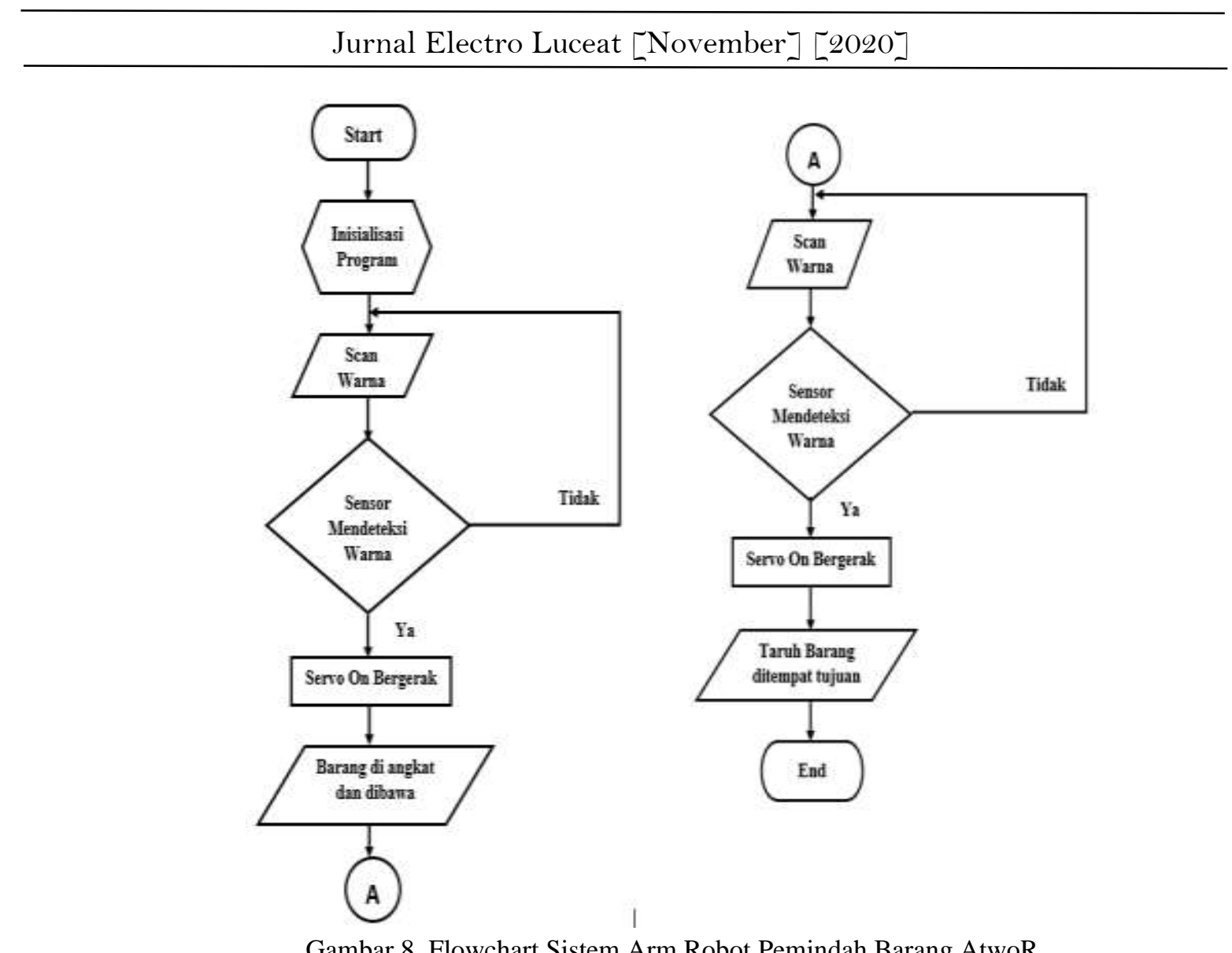

Gambar 8. Flowchart Sistem Arm Robot Pemindah Barang AtwoR

Arm robot pemindah barang (AtwoR) akan bergerak jika robot dihidupkan. Ketika robot dihidupkan, robot terlebih dahulu akan diletakan dijalur yang telah kami buat lalu robot akan mengikuti jalur dan mendekat ke barang atau objek, sensor warna akan aktif dan mendeteksi objek tersebut. Sensor warna akan mengirim data berupa data warna yang telah dideteksi menuju Arduino uno lalu Arduino uno akan mengirimkan kembali ke Arduino nano untuk selanjutnya diproses menuju Motor servo MG995. Motor servo Mg995 ini berfungsi sebagai penggerak dari lengan robot untuk mengambil suatu objek dan akan memindahkan objek sesuai data yang diperintah.

\section{PEMBAHASAN}

\subsection{Implementasi}

Implementasi ini bertujuan untuk mengetahui hasil perancangan AtwoR robot, sehingga pada bagian implementasi ini pembaca dapat mengetahui program serta perancangan yang telah dibuat.

\subsubsection{Implementasi Rangkaian AtwoR Robot}

Implementasi ini merupakan hasil dari perancangan yang telah dibuat. Mekanisme kerja sistem AtwoR robot adalah robot bekerja secara otomatis sesuai dengan intruksi yang telah diprogram. 


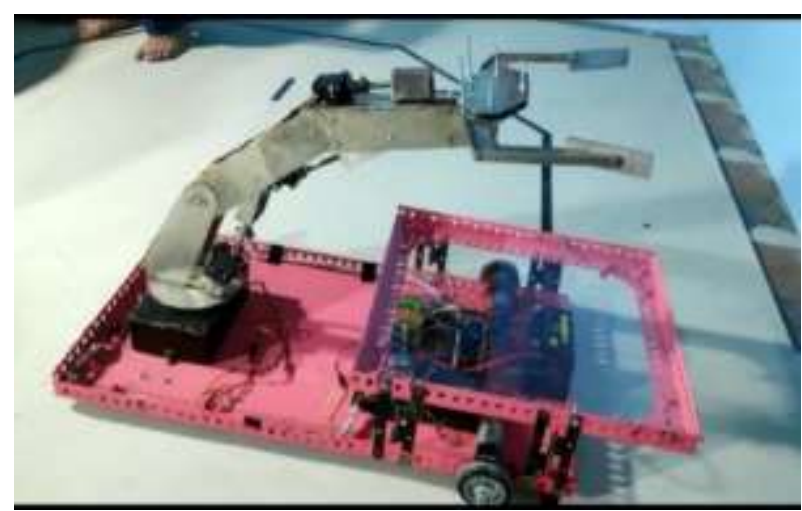

Gambar 9. Rangkaian AtwoR Robot

\subsubsection{Implementasi Rangkaian Arm Pemindah Barang}

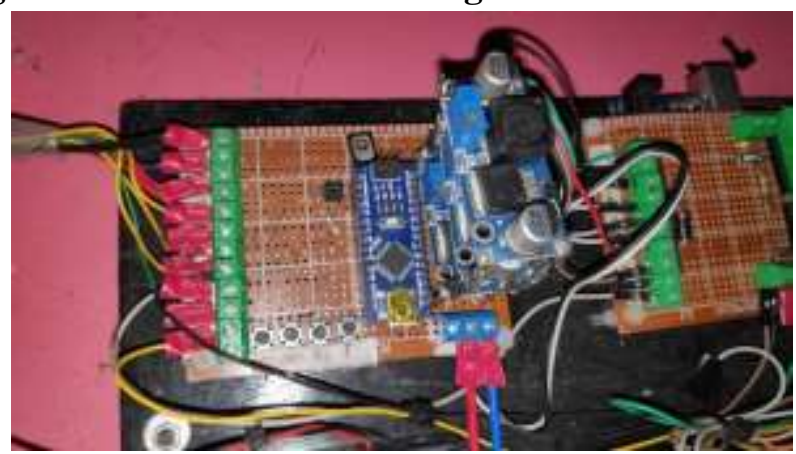

Gambar 10. Rangkaian Arm Robot Pemindah Barang

\subsubsection{Implementasi Motor Servo MG995 pada AtwoR Robot}

Pada bagian ini yaitu untuk menunjukan bagian masing - masing motor servo yang terletak dan sudah disusun pada arm robot pemindah barang, yang dimana posisi link dan joint arm robot sudah dirancang dengan sedemikian rupa.

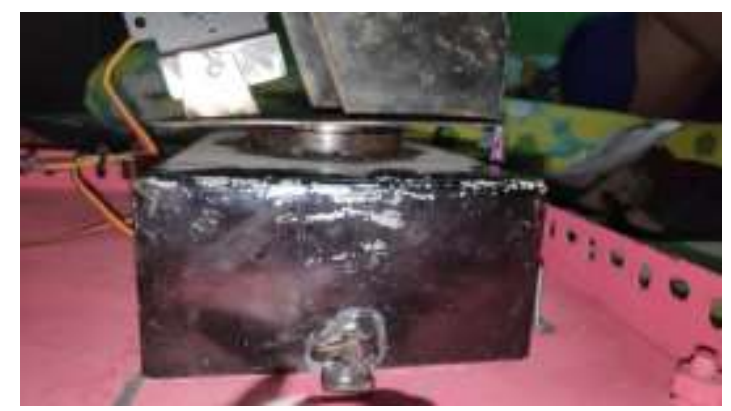

(a)

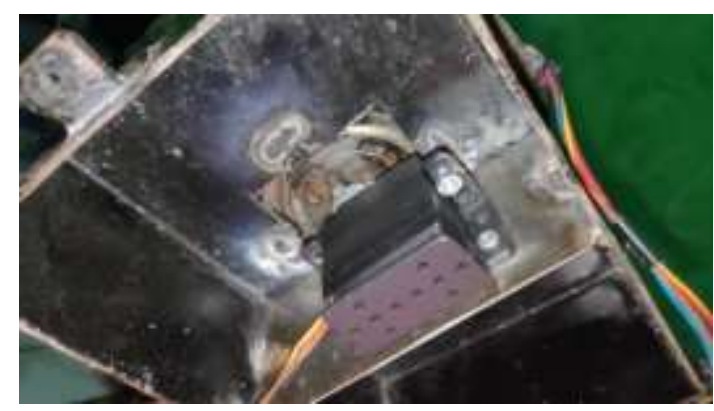

(b)

Gambar 11. Tata Letak Bagian Servo1 (Base) (a) Bagian Luar (b) Bagian Dalam 


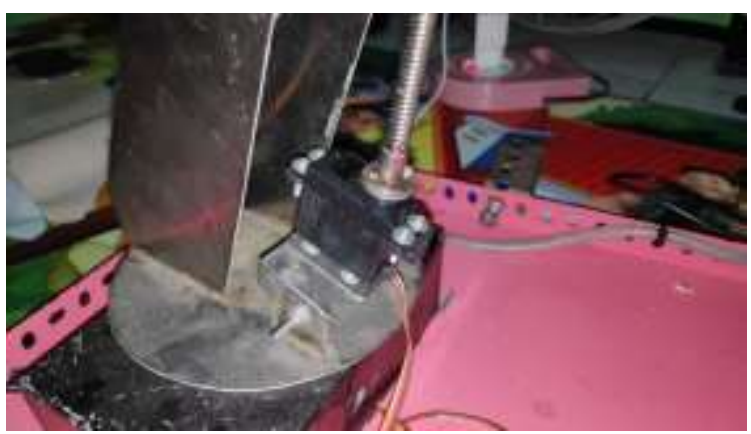

Gambar 12. Tata Letak Bagian Servo2 (Shoulder)

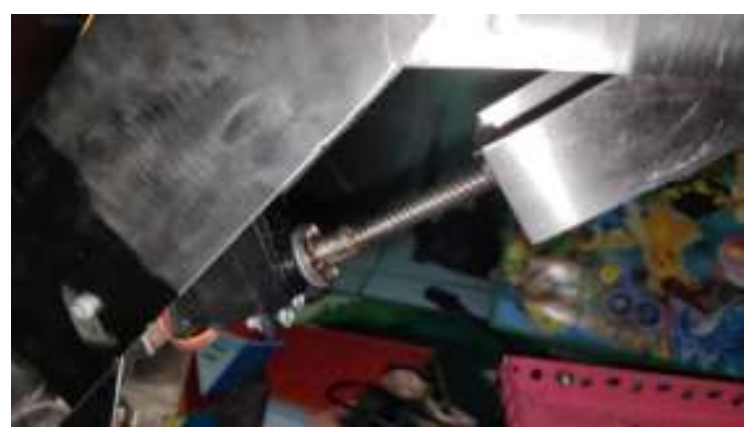

Gambar 13. Tata Letak Bagian Servo3 (Elbow)

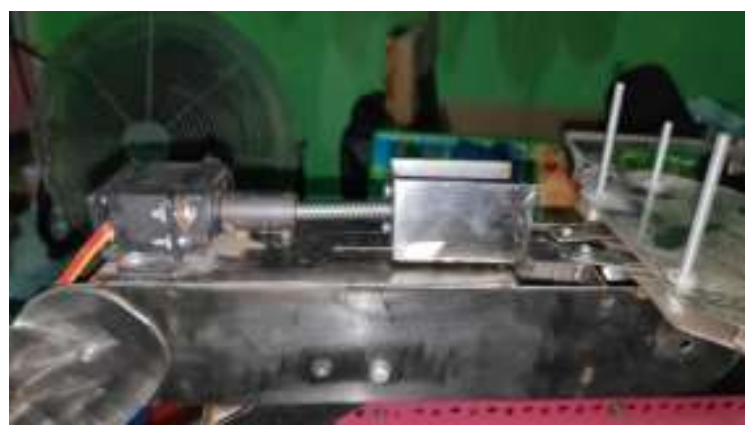

Gambar 14. Tata Letak Bagian Servo4 (Gripper)

\subsection{Pengujian}

Pengujian merupakan proses pengeksekusian alat. Pengujian dilakukan dengan melakukan percobaan untuk melihat kemungkinan yang terjadi dari setiap proses.

\subsubsection{Pengujian Daya Servo pada Lengan Robot}

Tabel 2. Daya Servo pada Lengan Robot

\begin{tabular}{|c|c|c|c|}
\hline No & Kontrol & Servo & Daya \\
\hline 1 & Base & 1 & $4.8 \mathrm{~V}$ \\
\hline 2 & Shoulder & 2 & $4.8 \mathrm{~V}$ \\
\hline 3 & Elbow & 3 & $4.8 \mathrm{~V}$ \\
\hline 4 & Gripper & 4 & $4.8 \mathrm{~V}$ \\
\hline
\end{tabular}

Dari hasil pengujian tersebut bahwa 4 servo untuk bagian lengan robot dapat menampung daya $4.8 \mathrm{~V}$ dengan kecepatan $0.19 \mathrm{sec} / 60 \mathrm{o}$ (posisi tanpa beban) bergerak dengan cukup baik. Hanya saja 
proses gripper untuk mengenggam belum cukup baik dikarenakan bentuk rancangan gripper lengan tidak bagus.

\subsubsection{Pengujian Putaran Servo Terhadap Lengan Robot}

Tabel 3. Putaran Servo Terhadap Lengan Robot

\begin{tabular}{|c|c|c|}
\hline No & Arah Putar & Bagian \\
\hline 1 & $90^{\circ}$ & Base \\
\hline 2 & $360^{\circ}$ & Shoulder \\
\hline 3 & $360^{\circ}$ & Elbow \\
\hline 4 & $360^{\circ}$ & Gripper \\
\hline
\end{tabular}

Dari hasil pengujian ini didapatkan hasil bahwa lengan robot dapat bergerak dengan baik, pada bagian bagian lengan dan sudut putar maksimal $360^{\circ}$ dan bisa berputar kembali ke arah sudut 0o. Masing-masing motor servo berputar yaitu servo1 $90^{\circ}$, Servo2 $360^{\circ}$, servo3 $360^{\circ}$, servo $460^{\circ}$. Pada bagian servo 2,3 dan 4 ini berputar secara terus menerus Counter wise $(\mathrm{CW})$ dan Counter Clock Wise $(C C W)$.

\subsubsection{Pengujian pada Masing - Masing Servo}

Tabel 4. Pengujian Masing - Masing Servo

\begin{tabular}{|c|c|c|c|c|c|}
\hline \multirow{2}{*}{ No } & \multirow{2}{*}{ Berat (gram) } & \multicolumn{4}{|c|}{ Durasi Putar Servo } \\
\cline { 3 - 6 } & & Servo 1 & Servo 2 & Servo 3 & Servo 4 \\
\hline 1 & 0 & 4 detik & 4 detik & 3 detik & 3 detik \\
\hline 2 & 100 & 4 detik & 5 detik & 4 detik & 3 detik \\
\hline 3 & 200 & 4 detik & 5 detik & 4 detik & 3 detik \\
\hline 4 & 300 & 4 detik & 4 detik & 5 detik & 3 detik \\
\hline 5 & 400 & 4 detik & 5 detik & 5 detik & 3 detik \\
\hline 6 & 500 & 4 detik & 5 detik & 5 detik & 3 detik \\
\hline 7 & 600 & 4 detik & 5 detik & 5 detik & 3 detik \\
\hline 8 & 700 & 5 detik & 5 detik & 6 detik & 3 detik \\
\hline \multicolumn{2}{|r}{ Nilai Rata - rata } & 4.12 detik & 4.75 detik & 4.62 detik & 3 detik \\
\hline
\end{tabular}

Dari pengujian di atas dapat disimpulkan bahwa durasi atau putaran pada masing - masing servo berbeda beda, durasi yang didapat tergantung seberapa berat objek yang diuji. Dan pada hasil uji ini hasil yang didapat kurang lebih 5 detik.

\subsubsection{Pengujian pada Lengan}

Tabel 5. Pengujian Lengan Robot

\begin{tabular}{|c|c|c|}
\hline No & Berat (gram) & Waktu yang didapat \\
\hline 1 & 0 & 14 detik \\
\hline 2 & 100 & 16 detik \\
\hline 3 & 200 & 16 detik \\
\hline 4 & 300 & 16 detik \\
\hline 5 & 400 & 17 detik \\
\hline 6 & 500 & 17 detik \\
\hline
\end{tabular}


JEC VOL. 6 NO. 2

Jurnal Electro Luceat [November] [2020]

\begin{tabular}{|c|c|c|}
\hline 7 & 600 & 17 detik \\
\hline 8 & 700 & 19 detik \\
\hline \multicolumn{2}{|c|}{ Nilai Rata - rata } & 16.5 detik \\
\hline
\end{tabular}

Dari pengujian di atas dapat disimpulkan bahwa durasi atau putaran yang didapat pada lengan robot durasi yang didapat tergantung seberapa berat objek yang diuji. Dan pada hasil uji ini hasil yang didapat kurang lebih 16 detik.

\subsubsection{Pengujian Beban Terhadap Servo}

Tabel 6. Hasil Uji Beban Terhadap Lengan

\begin{tabular}{|c|c|c|c|c|}
\hline \multirow{2}{*}{ No } & \multirow{2}{*}{ Pengujian } & \multirow{2}{*}{ Berat (gram) } & \multicolumn{2}{|c|}{ Hasil } \\
\cline { 4 - 5 } & & & Berhasil & Tidak \\
\hline $\mathbf{1}$ & Dus 1 & 0 & Ya & \\
\hline $\mathbf{2}$ & Dus 2 & 100 & Ya & \\
\hline $\mathbf{3}$ & Dus 3 & 200 & Ya & \\
\hline $\mathbf{4}$ & Dus 4 & 300 & Ya & \\
\hline $\mathbf{5}$ & Dus 5 & 400 & Ya & \\
\hline $\mathbf{6}$ & Dus 6 & 500 & Ya & \\
\hline $\mathbf{7}$ & Dus 7 & 600 & Ya & No \\
\hline $\mathbf{8}$ & Dus 8 & 700 & & \\
\hline
\end{tabular}

Dari pengujian diatas dapat disimpulkan bahwa lengan robot ini dapat mengangkat beban dengan berat maksimal 700 gram dan lebar objek genggaman $\pm 25 \mathrm{~cm}$. Daya dan kinetik pada lengan robot adalah sama karena menggunakan jenis servo yang sama, hanya geraknya saja yang berbeda.

\section{KESIMPULAN}

\subsection{Kesimpulan}

Berdasarkan hasil yang diperoleh dari penelitian yang telah dilakukan, dapat disimpulkan bahwa:

1. Dari pengujian motor servo MG995 pada Arm robot pemindah barang bahwa kekuatan Arm pada robot pemindah barang maksimum beban dus yang mampu dibawa lengan robot pada proses pengujian yaitu 700 gram.

2. Dari pengujian ini perancangan Arm robot pada robot pemindah barang dianggap berhasil, hasil nilai rata - rata durasi yang didapat masing - masing servo MG995, yaitu servo1 $=4.12$ detik, servo $2=4.75$ detik, servo3= 4.62 detik, servo4= 3 detik. Untuk hasil keseluruhan Arm bergerak, yaitu 16.5 detik,

3. Dari perancangan arm robot ini hasil putaran yang didapatkan masing-masing motor servo MG995 untuk menyesuaikan dengan objek dalam metode ulir ini yaitu servo1 $90^{\circ}$, Servo2 $360^{\circ}$, servo3 $360^{\circ}$, servo4 $360^{\circ}$. Pada bagian servo 2,3 dan 4 ini berputar secara terus menerus Counter wise (CW) dan Counter Clock Wise (CCW). 


\subsection{Saran}

Saran ini ditunjukan untuk pengembangan alat berikutnya. Yang dapat diharapkan bisa memperbaiki kekurangan yang sudah diteliti dalam penelitian ini:

1. Untuk penelitian selanjutnya sebaiknya gunakan motor servo dengan torsi yang lebih besar pada perancangan bagian Arm robot pada robot pemindah barang AtwoR agar dapat membawa barang atau dus dengan ukuran lebih besar.

2. Selain itu buatlah rancangan Arm pada robot pemindah barang sepresisi mungkin agar gripper dan bagian bagian lainnya seperti base, shoulder, dan elbow dapat bekerja dengan baik.

\section{DAFTAR PUSTAKA}

[1] I, Muhammad, Rancang Bangun Trainer Alat Penyortir Barang Logam dan Non Logam Sebagai Media Pembelajaran pada Mata Kuliah Dasar Sistem Kontrol, Semarang: Universitas Negeri Semarang, 2016.

[2] N.W. Deny, "Pengendalian Robot Yang Memiliki Lima Derajat Kebebasan," Jurnal Ilmiah Foristek, vol. I, no. 1, p. 22, 2011.

[3] W. Budiharto, "Membuat Sendiri Robot Cerdas (Edisi Revisi)", jakarta: Elex Media Komputindo, 2009.

[4] G. R. Anandya, Rancang Bangun Lengan Robot Penjepit PCB 3 DOF Berbasis Arduino Untuk Proses Etching PCB Otomatis, Surabaya: Institut Teknologi Sepuluh Nopember, 2017.

[5] F. Djuandi, "Pengenalan Arduino", E-book, 2011.

[6] D. D. Yudhistira, M. D. Ramadhan, N. Augusta dan S. Agustini, "Pengenalan Mikrokontroler Arduino Uno," pp. 1-7, 2015.

[7] N. M. H. Pratama, "Rancang Bangun Deteksi Stress Pada Sistem Pemantau Kesehatan Manusia Berbasis Arduino Nano," pp. 11-12, 2018.

[8] M. Riza Fauzi Rahman, Sistem Kendali Robot Lengan Empat DOF Berbasis Pengolahan Citra Dengan Sensor Kamera Kinect, Yogyakarta: UGM, 2018.

[9] Thowil Afif, Muhammad; Putri Pratiwi, Ilham Ayu, "Analisis Perbandingan Baterai LithiumIon, Lithium-Polymer, Lead Acid dan Nickel-Metal Hydride pada Penggunaan Mobil Listrik Review," Jurnal Rekayasa Mesin , vol. 6, no. 2, p. 95, 2015.

[10] Maulana Yusuf, Muhamad; Mardiono; Lestari, Sri Wiji, "Rancang Bangun Alat Pemilah Barang Berdasarkan Warna dan Berat," Jurnal Teknologi, vol. 6, no. 2, p. 137, 2019.

[11] Adriansyah, Andi; Hidyatama, Oka, "Rancang Bangun Prototype Elevator Menggunakan Microcontroller Arduino ATMEGA 328P," Jurnal Teknologi Elektro, vol. 4, no. 3, p. 104, 2013. 